\title{
Brain involvement in H7N9 bird flu: a topic for consideration
}

\section{Envolvimento cerebral na gripe aviária H7N9: um tópico para consideração}

The new emerging infection due to H7N9 influenza virus in China is the latest new outbreak for global concern ${ }^{1}$. As a bird flu, this infection is considered a zoonosis and results in serious clinical illness. As an atypical influenza infection, the classical febrile illness and respiratory problems might be modified by many atypical clinical manifestations ${ }^{2,3}$. Other organ involvement is common, especially for serious cases. Other organ involvement has been described and involvement of the brain is of concern ${ }^{2,3}$. Indeed, the neurological problems due to the new influenza is an interesting topic in neurology ${ }^{4}$, and the present scenario of H7N9 bird flu should be focused on this. In bird flu, there are previous reports on brain pathology in other problematic strains, such as H5N1. Lu et al. ${ }^{5}$ have described the main pathology as "edema with cytoplasmic eosinophilia, loss of structure, axon welling and focal necrosis around ventricle." Kristensson ${ }^{6}$ noted that "avian influenza subtypes have the propensity to invade the brain along cranial nerves to target brainstem and diencephalic nuclei" and we should be aware of this during the present outbreak H7N9 influenza. Observation for neurological problems in patients and further study on this topic are the challenges facing neurologists.

Somsri Wiwanitkit ${ }^{1}$, Viroj Wiwanitkit ${ }^{2}$

\section{References}

\footnotetext{
1. Eurosurveillance editorial team. Novel influenza $A(H 7 N 9)$ virus linked to human disease in China, April 2013. Euro Surveill 2013;18(14):pii=20445.

2. Lu SH, Xi XH, Zheng YF, Cao Y, Liu XN, Lu HZ. Analysis of the clinical characteristics and treatment of two patients with avian influenza virus (H7N9). Biosci Trends 2013;7:109-112.

3. Gao R, Cao B, Hu Y, et al. Human infection with a novel avian-origin influenza A (H7N9) Virus. N Engl J Med 2013;368:1888-1897.
}

4. Wiwanitkit V. Neurological manifestation of Swine flu: a brief note. Acta Neurol Taiwan 2010;19:145-147.

5. Lu M, Xie ZG, Gao ZC, et al. Histopathologic study of avian influenza H5N1 infection in humans. Zhonghua Bing Li Xue Za Zhi 2008;37:145-149.

6. Kristensson K. Avian influenza and the brain - comments on the occasion of resurrection of the Spanish flu virus. Brain Res Bull 2006;68:406-413.

1 Wiwanitkit House, Bangkhae, Bangkok Thailand;

${ }^{2}$ Visiting Professor, Hainan Medical University, China.

Correspondence: Somsri Wiwanitkit; Wiwanitkit House, Bangkhae, Bangkok Thailand; E-mail: somsriwiwan@hotmail.com

Conflict of interest: There is no conflict of interest to declare.

Received 27 April 2013; Received in final form 15 May 2013; Accepted 22 May 2013. 